Tạp chí Khoa học và Công nghệ biển T11 (2011). Số 1. Tr 85 - 96

\title{
MộT SỐ KÊTT QUẢ THỰC NGHIỆM TRỔNG PHỤC HỒI SAN HÔ TẠI QUẦ ĐẢo Cô Tô DỰA VÀO CộNG ĐỒNG
}

\section{NGUYẼ̃N ĐỨC CỰ, NGUYẼ̃N ĐĂNG NGẢI, ĐÀO TH!̣ ÁNH TUYÊT, NGUYẼ̃ VĂN THẢO, NGUYẼ̃N XUÂN THÀNH, NGUYẼ̃N ĐỨC TOÀN, ĐOÀN TH!̣ NHINH}

\author{
Viện Tài nguyên và Môi trường biển
}

\begin{abstract}
Tóm tắt: Trồng phuc hồi san hô kết hơp với cộng đồng cu dân địa phương đã được thực hiện tại 03 khu vưc thuộc quần đảo Cô Tô (tỉnh Quảng Ninh) đã đurợc bảo vệ là hòn Khe Trâu, hòn Đặng Văn Châu (Tài Vạn Cháu) và hòn Khe Con. Năm 2008 đã trồng đurợc tổng số 232 tập đoàn san hô trên 29 giá thể nhân tạo là giá thể bê tông dạng vòm và 95 tập đoàn san hô trên giá thể tư nhiên. Kết quả theo dõi san hô sau 1 năm trồng phục hồi cho kết quả 10 giống san hô được trồng đều có thể sủ dụng để trồng phuc hồi được với tỷ lệ sống rất cao, đạt trên $94 \%$ ở giá thể nhân tạo dạng vòm và đạt tù 70 - $86 \%$ trên giá thể tụ nhiên. Tốc độ tăng trưởng trung bình sau 1 năm trồng đều đạt trên $1,00 \mathrm{~cm} / n a ̆ m$.

Lỗi kỹ thuật từ quá trình buộc gắn các tập đoàn san hô vào giá thể và mối đe dọa tù sự phát triển của địch hại san hô - ốc Drupella là nguyên nhân làm giảm tỷ lệ sống của san hô trồng phục hồi nhân tạo ở các khu vục này.
\end{abstract}

\section{MỞ ĐÀ̀U}

Quần đảo Cô Tô (tỉnh Quảng Ninh) đã từng là nơi có diện tích và độ phủ rạn san hô thuộc loại lớn nhất khu vực miền Bắc. Chính hệ sinh thái rạn san hô này đã tạo ra cho vùng biển này sự đa dạng sinh học và nguồn lợi hải sản rất phong phú. Việc đánh bắt quá mức và sử dụng các hình thức khai thác huỷ diệt đã làm cho nguồn lợi ngày càng cạn kiệt. Đặc biệt, việc sử dụng chất độc cyanua, xung điện, mìn để đánh bắt hải sản đã tàn phá hệ sinh thái rạn san hô (mái nhà của các loài hải sản), huỷ diệt tất các các loài trong phạm vi ảnh hưởng, làm mất cân bằng sinh thái dẫn đến phát triển mạnh một số tác nhân gây hại cho san hô như rong, thân mềm.

Sự mất đi hệ sinh thái rạn san hô trong những năm gần đây tại quần đảo Cô Tô đã làm quá trình tái tạo nguồn lợi ngày càng khó khăn hơn. Chính vì vậy, để có sự phát triền bền vững nguồn lợi tự nhiên, trồng phục hồi san hô kết hợp với cộng đồng cư dân địa phương cùng tham gia quản lý là một định hướng dài hạn và đúng đắn. Qua đó, sẽ nâng cao ý thức cộng đồng về vai trò và tầm quan trọng của rạn san hô, tác hại lâu dài của việc 
khai thác huỷ diệt đến đời sống của chính họ và thế hệ tương lai. Bài báo này cung cấp một số kết quả bước đầu của quá trình phục hồi san hô do các cán bộ nghiên cứu của Viện Tài nguyên và Môi trường Biển đã cùng với ngư dân địa phương thực hiện trong 2 năm, từ năm 2008 - 2009 tại hòn Khe Trâu, hòn Đặng Văn Châu và hòn Khe Con thuộc quần đảo Cô Tô.

\section{TÀI LIỆU VÀ PHƯƠNG PHÁP}

\section{Tài liệu}

Tài liệu trong bài báo là kết quả nghiên cứu của tập thể đề tài "Nghiên cưu khả năng phục hồi hệ sinh thái san hô và triển khai mô hình quản lý cộng đồng tại quần đảo Cô Tô" thực hiện trong năm 2008 và năm 2009 theo yêu cầu của tỉnh Quảng Ninh.

\section{Phương pháp}

\subsection{Nguồn giống và phương thức vận chuyển}

- Nguồn giống chủ yếu là lấy ngay tại chỗ gồm các loài sống phổ biến tại khu vực Cô Tô.

- San hô giống được vận chuyển bằng phương pháp ướt, sử dụng sọt nhựa để vận chuyển san hô từ dưới rạn lên sau đó chuyển sang các chậu hoặc khay nước lớn có sục khí đảm bảo chúng không bị khô và tránh ánh nắng chiếu trực tiếp lên san hô.

\subsection{Phương pháp trồng phục hồi san hô}

- Trồng san hô trên giá thể nhân tạo: giá thể là bê tông dạng vòm (reefball): đường kính $1 \mathrm{~m}$, cao $0,8-1 \mathrm{~m}$, có $14-16$ lỗ, đường kính mỗi lỗ từ $5-12 \mathrm{~cm}$ trong đó có 8 lỗ để trồng san hô và 6 lỗ cho sinh vật chui vào cư trú. Dạng giá thể này được đặt ở những nơi có đáy là cát hoặc vụn san hô chết. Đặt san hô vào các lỗ trên giá thể, dùng dây cước buộc chặt sao cho tập đoàn san hô áp sát vào giá thể và không bị lung lay do sóng hoặc dòng chảy. Mỗi giá thể trồng 8 tập đoàn san hô.

- Trồng san hô trên giá thể tự nhiên: chọn những chỗ có nền đáy sạch là nền đá hoặc san hô chết không có bùn, rong bám. Dùng đinh thép dài từ $15-20 \mathrm{~cm}$ đóng xuống nền đá san hô chết, ngập sâu khoảng $10 \mathrm{~cm}$. Sau đó, buộc cố định san hô vào đinh thép bằng cách sử dụng dây nhựa thắt xiết chặt sao cho san hô được cột chặt vào đinh thép, đồng thời phải áp sát vào nền đáy để chúng có thể bám đáy được.

Tất cả các tập đoàn được trồng trên giá thể đều được đánh dấu bằng thẻ có đánh số và đo kích thước tập đoàn để theo dõi tốc độ sinh trưởng, tỷ lệ sống/chết. 
Độ sâu đặt giá thể 3 - $10 \mathrm{~m}$, khoảng cách giữa các giá thể là $5 \mathrm{~m}$. Sau khi thả xuống, cần phải xắp xếp lại các giá thể theo hàng lối, đặt vào những chỗ có nền đáy bằng phẳng.

Thời gian trồng: được tiến hành vào tháng $8 / 2008$ và được kiểm tra lại vào tháng $11 / 2008$ và tháng $8 / 2009$.

\subsection{Lựa chọn địa điểm trồng và tổ chức trồng}

- Lựa chọn điểm trồng: Các khu vực trồng phục hồi san hô được lựa chọn dựa trên các điều kiện sau: là nơi trước kia đã có rạn san hô phân bố và gần nguồn san hô giống; có chất lượng nước tốt, nền đáy sạch không bị lắng đọng trầm tích, không bị rong bám; là nơi đã có căn cứ pháp lý để thuận lợi cho công tác quản lý sau khi trồng. Được sự đồng ý tham gia quản lý kết hợp của các hộ dân các đảo và dựa vào kết quả khảo sát thực tế hiện trạng, chúng tôi đã thực hiện trồng phục hồi nhân tạo san hô tại các khu vực: Hòn Khe Trâu (2058'30’'N - 107 47'16’E), Hòn Đặng Văn Châu (hòn Tài Vạn Cháu - 2059’06”N

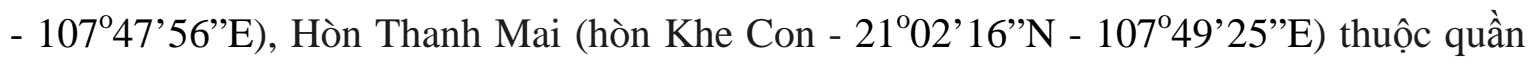
đảo Cô Tô.

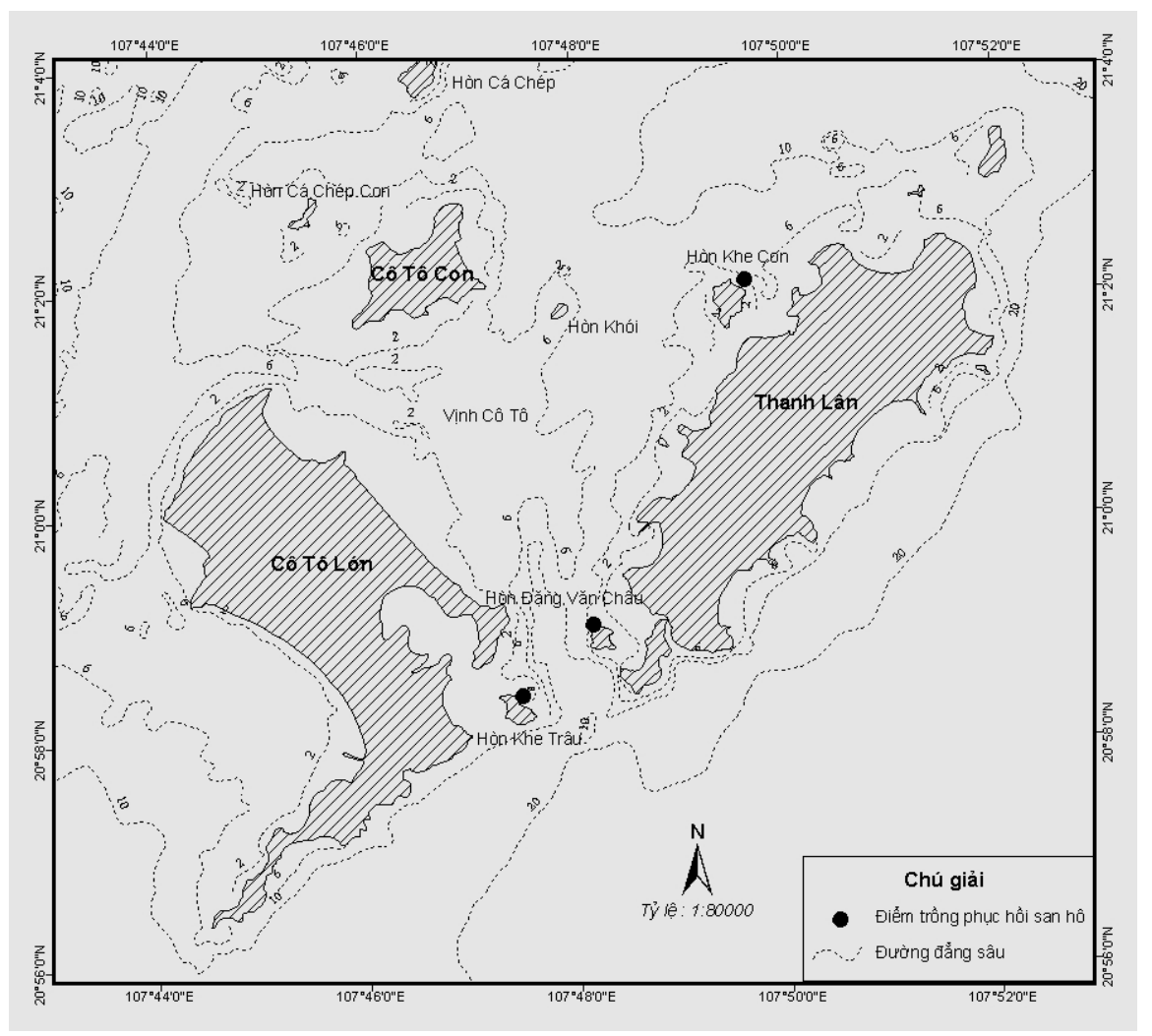

Hình 1: Các khu vực trồng san hô tại quần đảo Cô Tô 
Theo số liệu quan trắc của chúng tôi tại các khu vực này vào tháng 12/2007, tháng 4/2008 và tháng 7/2008, nhiệt độ nước trong năm dao động trong khoảng $16-31^{\circ} \mathrm{C}$, độ mặn ổn định trong khoảng $30-33 \%$, dòng chảy nhẹ $(0,15-1 \mathrm{~m} / \mathrm{s})$, độ trong cao; hàm lượng các muối dinh dưỡng nitơ và phốtpho đều thấp hơn nhiều lần so với tiêu chuẩn cho phép. Chất đáy của 3 khu vực trồng phục hồi san hô chủ yếu là đá và san hô chết, không có rong bao phủ và không có lắng đọng trầm tích phù hợp với sự phát triển của san hô.

- Tổ chức trồng phục hồi: Tổ chức trồng thành nhiều đợt (trồng thử nghiệm và trồng mở rộng). Trong mỗi đợt, các cán bộ của Viện Tài nguyên và Môi trường biển kết hợp với các tình nguyện viên tại từng khu vực cùng tham gia trồng. Ngoài việc cùng tham gia trồng phục hồi, người dân còn nhận trách nhiệm trông coi và giám sát sự phát triển của san hô.

\subsection{Hoạt động của nhóm cộng đồng tham gia vào quá trình trồng phục hồi và bảo vệ san hô}

Thành phần tham gia trồng phục hồi thử nghiệm bao gồm 6 cán bộ của Viện Tài nguyên và Môi trường biển, người đại diện quản lý của khu vực trồng phục hồi và mỗi điểm trồng có 5 - 10 tình nguyện viên tham gia. Hạn chế của nhóm cộng đồng là hầu hết các tình nguyện viên trong nhóm cộng đồng trên quần đảo Cô Tô chưa có chứng chỉ lặn được cơ quan có thẩm quyền cấp nên vì lý do an toàn và tính hợp pháp của hoạt động, người dân tình nguyện trồng phục hồi chỉ có thể tham gia vào được vào một số công đoạn trồng phục hồi san hô nhất định như: buộc cố định tập đoàn san hô vào giá thể, gắn thẻ, xác định các thông số đo, thả giá thể... Tuy nhiên, việc nhóm tình nguyện cùng tham gia vào một số khâu quan trọng trong quá trình trồng phục hồi san hô sẽ giúp cho người dân hiểu rõ hơn về tầm quan trọng của hệ sinh thái rạn san hô đối với môi trường và cộng đồng, nắm rõ các thao tác cơ bản của quá trình trồng phục hồi và ý nghĩa thực tiễn của công việc.

Sau quá trình trồng phục hồi, người đại diện quản lý của khu vực trồng phục hồi cùng với nhóm tình nguyện sẽ chịu trách nhiệm chính trong việc trông coi và bảo vệ các khu vực trồng san hô; giám sát và ngăn ngừa các hoạt động gây ảnh hưởng xấu đến sinh trưởng và phát triển của san hô.

\section{KẾT QUẢ VÀ THẢO LUẬN}

\section{Kết quả}

Tháng 8/2008, các cán bộ của Viện Tài nguyên và Môi trường biển cùng với cộng đồng cư dân địa phương đã tiến hành trồng được 232 tập đoàn san hô trên 29 giá thể nhân 
tạo dạng vòm và 95 tập đoàn san hô phủ trên diện tích $165 \mathrm{~m}^{2}$ tại các khu vực trồng thuộc quần đảo Cô Tô.

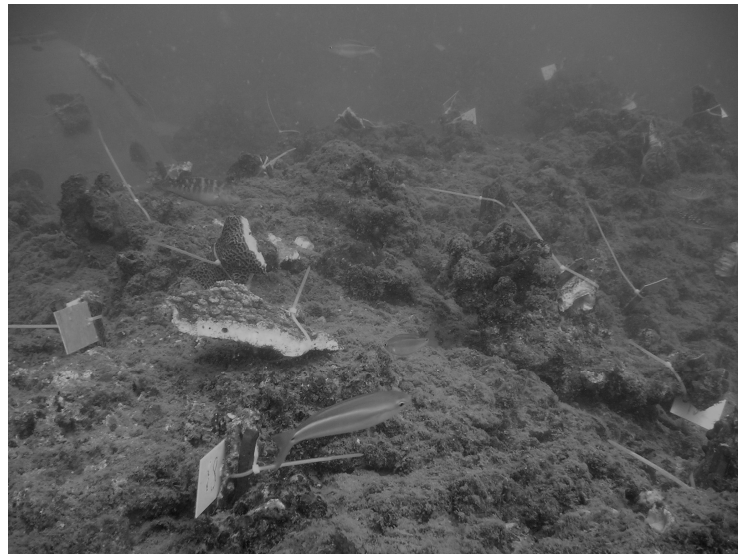

Hình 2: San hô trồng trên giá thể tự nhiên tháng 8/2008

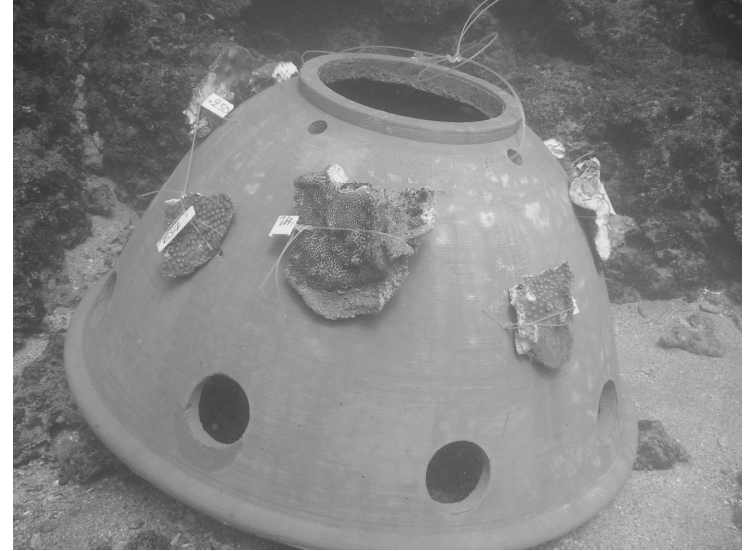

Hình 3: San hô trồng trên giá thể nhân tạo tháng 8/2008

\subsection{Hiệu quả trồng phục hồi san hô tại khu vục hòn Khe Trâu}

Tại đây, đã trồng được san hô trên 11 giá thể nhân tạo dạng vòm, gồm 88 tập đoàn san hô và trồng được phần diện tích khoảng $55 \mathrm{~m}^{2}$ trên giá thể tự nhiên với 30 tập đoàn san hô.

\section{a. Kết quả trồng san hô trên giá thể nhân tạo}

Một số loài san hô chiếm ưu thế là Platygyra và Enchynophyllia được sử dụng để làm san hô giống.

Bảng 1: Kết quả trồng san hô trên giá thể nhân tạo tại hòn Khe Trâu

\begin{tabular}{|c|c|c|}
\hline Tên giống & Số tập đoàn trồng & $\begin{array}{c}\text { Mức tăng trưởng trung bình } \\
\text { (cm/tập đoàn/năm) }\end{array}$ \\
\hline Echinophyllia & 19 & 1,98 \\
\hline Plesiastrea & 1 & 2,7 \\
\hline Galaxea & 3 & 2,1 \\
\hline Goniopora & 11 & 1,69 \\
\hline Pavona & 2 & 1,2 \\
\hline Platygyra & 42 & 2,09 \\
\hline Porites & 2 & 1 \\
\hline Turbinaria & 8 & 2,47 \\
\hline
\end{tabular}


Hầu hết san hô đều tăng trưởng sau 1 năm trồng phục hồi, tốc độ của các giống dao động trong khoảng từ $1-2,47 \mathrm{~cm}$. Sau khi thả giá thể đã có thể quan sát thấy các xúc tu trên các tập đoàn san hô đã hoạt động trở lại, màu sắc tươi sáng và thò ra để bắt mồi. Ba tháng sau khi trồng, nhiều tập đoàn đã phát triển bám vào giá thể và trùm lên phần dây buộc. Phần trong khung giá thể dạng vòm đã có nhiều loài sinh vật cư trú như cá, giáp xác, trên giá thể đã có nhiều thực vật, nhuyễn thể cùng sinh sống.

Trong số 88 tập đoàn đã trồng, chỉ có 2 tập đoàn bị chết, 1 tập đoàn bị tuột khỏi giá thể vào tháng $8 / 2008$. Trong lần kiểm tra vào tháng $8 / 2009$, có thêm 2 tập đoàn san hô bị chết. Như vậy, tỷ lệ sống của san hô sau 1 năm trồng phục hồi tại Cô Tô khá cao, đạt 94,3\%. Một trong các lý do có thể đạt được tỷ lệ sống cao như vậy là do việc lựa chọn nguồn giống san hô tại chỗ thích ứng với môi trường địa phương.

Nguyên nhân san hô bị chết: 2 tập đoàn san hô bị chết trong 3 tháng đầu có thể do san hô bị sốc khi đục tách từ tập đoàn lớn, 1 tập đoàn bị tuột do thao tác buộc chưa được chặt nên sóng và dòng chảy làm tập đoàn này rơi ra khỏi giá thể. Có 2 tập đoàn bị chết trong khoảng thời gian từ 11/2008 - 8/2009 có thể do xuất hiện có một số sinh vật gây hại cho san hô. Đó chính là ốc Drupella chuyên ăn thịt san hô sống như đã phát hiện trong đợt kiểm tra vào tháng 8/2009: trên 11 giá thể tại Khe Trâu, đã đếm được 9 tập đoàn đang bị ốc ăn một phần hoặc ăn hêt.

\section{b. Kết quả trồng san hô trên giá thể tự nhiên}

Với các tập đoàn san hô được trồng trực tiếp trên nền đáy, kết quả theo dõi tỷ lệ sống và quá trình sinh trưởng của chúng trên giá thể tự nhiên tại hòn Khe Trâu được tổng hợp trong bảng 2 .

Bảng 2: Kết quả trồng san hô trên giá thể tự nhiên tại hòn Khe Trâu

\begin{tabular}{|c|c|c|}
\hline Tên giống & Số tập đoàn theo dõi & $\begin{array}{c}\text { Mức tăng trưởng trung bình } \\
\text { (cm/tập đoàn/năm) }\end{array}$ \\
\hline Plesiastrea & 1 & - \\
\hline Echinophyllia & 5 & 2,43 \\
\hline Galaxea & 1 & - \\
\hline Goniopora & 1 & 1,7 \\
\hline Pavona & 2 & 3,3 \\
\hline Platygyra & 17 & 2,42 \\
\hline Turbinaria & 3 & 2,35 \\
\hline
\end{tabular}


Trên giá thể tự nhiên tốc độ phát triển trung bình của các tập đoàn dao động trong khoảng từ $1,7-3,3 \mathrm{~cm} /$ năm. Trong 30 tập đoàn được trồng có 5 tập đoàn bị chết (trong đó có 2 tập đoàn mới chết có thể là do ốc ăn), 4 tập đoàn bị tuột khỏi giá thể và 2 tập đoàn đang bị ốc ăn. Như vậy tỷ lệ sống trên giá thể tự nhiên đạt $70 \%$, thấp hơn so với giá thể nhân tạo. Nguyên nhân là do việc thao tác buộc san hô dưới nước khó khăn hơn, buộc không chặt, do vậy san hô dạng khối thường hay bị tuột hoặc bị đung đưa theo nước nên dễ bị chết. Đồng thời, trên các giá thể tự nhiên cũng xuất hiện của ốc ăn san hô, làm san hô chết.

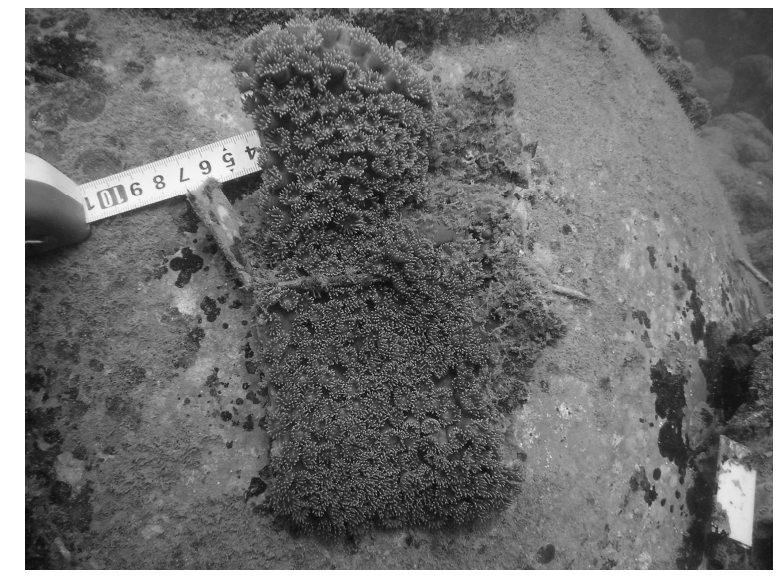

Hình 4: Sau một năm trồng san hô đã phát triển trùm lên dây buộc và bám vào giá thể

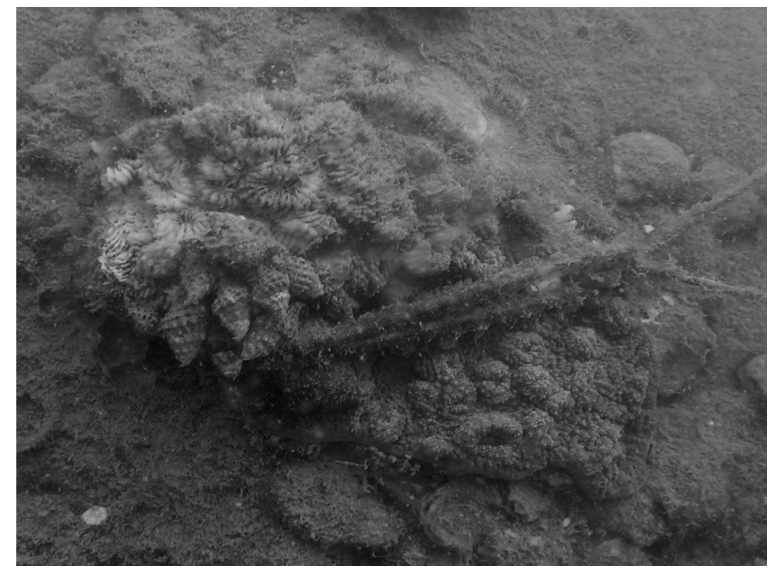

Hình 5: Ốc Drupella đang ăn tập đoàn san hô Echinophyllia

\subsection{Hiệu quả trồng phục hồi san hô tại khu vục tại khu vục Đặng Văn Châu}

Tại khu vực Đặng Văn Châu, đã tiến hành trồng trên tổng số 10 giá thể nhân tạo với 80 tập đoàn và 35 tập đoàn trồng trên giá thể tự nhiên trên diện tích khoảng $65 \mathrm{~m}^{2}$. San hô giống sử dụng trong quá trình trồng là san hô chiếm ưu thế trong khu vực này, giống Turbinaria.

\section{a. Kết quả trồng san hô trên giá thể giá thể nhân tạo}

Sau một năm trồng phục hồi cho kết quả tỷ lệ sống san hô khá cao, đạt $95 \%$, chỉ có 4 tập đoàn bị chết, tốc độ phát triển trung bình dao động trong khoảng từ $1,3-3,2 \mathrm{~cm} / \mathrm{năm}$. Có 2 tập đoàn bị tuột do buộc chưa chặt vì nhiều tập đoàn dạng khối tròn nên rất khó buộc. Đặc biệt ở khu vực này cũng phát hiện thấy có 5 tập đoàn bị ốc Drupella ăn, chiếm tỷ lệ 6,25\% số tập đoàn được trồng. Một số tập đoàn mới chết đây cũng có thể nguyên nhân là do ốc ăn. Một số tập đoàn đã bi ốc ăn hết để lại bộ xương san hô còn mới (trắng) nhưng chúng vẫn chưa di chuyển sang tập đoàn khác. 
San hô phát triển tốt, nhiều tập đoàn đã bám gắn vào giá thể và trùm lên phần dây buộc. Trên giá thể đã có nhiều ốc nón và nhiều loài cá cư trú. Chưa thấy ấu trùng san hô bám tự nhiên vào giá thể.

Bảng 3: Kết quả trồng san hô trên giá thể nhân tạo tại hòn Đặng Văn Châu

\begin{tabular}{|c|c|c|}
\hline Tên giống & Số tập đoàn trồng & $\begin{array}{c}\text { Mức tăng trưởng trung bình } \\
\text { (cm/tập đoàn/năm) }\end{array}$ \\
\hline Plesiastrea & 4 & 2,23 \\
\hline Echinophyllia & 2 & 3,2 \\
\hline Favites & 1 & 1,3 \\
\hline Goniopora & 2 & 1,55 \\
\hline Turbinaria & 71 & 2,41 \\
\hline
\end{tabular}

\section{b. Kết quả trồng san hô trên giá thể tự nhiên}

Tỷ lệ sống của san hô trồng trên giá thể tự nhiên tại khu vực này rất cao, đạt $100 \%$ sau 3 tháng trồng. San hô trồng trên các giá thể tự nhiên cũng phát triển tốt. Sau một năm, có 3 tập đoàn bị tuột và 4 tập đoàn đang bị ốc ăn. Tốc độ phát triển trung bình dao động trong khoảng từ $1,2-2,4$ cm/năm và tỷ lệ sống đạt $80,5 \%$ (bảng 4).

Bảng 4: Kết quả trồng san hô trên giá thể tự nhiên tại khu vực Đặng Văn Châu

\begin{tabular}{|c|c|c|}
\hline Tên giống & Số tập đoàn trồng & $\begin{array}{c}\text { Mức tăng trưởng trung bình } \\
\text { (cm/tập đoàn/năm) }\end{array}$ \\
\hline Plesiastrea & 1 & 2,4 \\
\hline Echinophyllia & 1 & 1,7 \\
\hline Favites & 1 & 1,2 \\
\hline Goniopora & 1 & - \\
\hline Turbinaria & 31 & 2,38 \\
\hline
\end{tabular}

Như vậy, tại điểm này có thể thấy quá trình buộc gắn các tập đoàn san hô vào các giá thể và địch hại đã làm ảnh hưởng đến tỷ lệ sống. Nếu khắc phục được nhược điểm này thì tỷ lệ sống của san hô trồng phục hồi trên giá thể tự nhiên sẽ đạt rất cao. 


\subsection{Hiệu quả trồng phục hồi san hô tại khu vục hòn Khe Con (Thanh Mai)}

Tại khu vực hòn Khe Con, giống san hô chiếm ưu thế trồng trong khu vực này là Plesiastrea.

\section{a. Kết quả trồng san hô trên giá thể nhân tạo}

Đã tiến hành trồng được 8 giá thể nhân tạo với 64 tập đoàn san hô. Kết quả tăng trưởng sau 1 năm được thể hiện trong bảng 5 .

Bảng 5: Kết quả trồng san hô trên giá thể nhân tạo tại Khe Con

\begin{tabular}{|c|c|c|}
\hline Tên giống & Số tập đoàn trồng & $\begin{array}{c}\text { Mức tăng trưởng trung bình }(\mathbf{c m} / \mathbf{t a ̣ ̂ p} \\
\text { đoàn/năm })\end{array}$ \\
\hline Plesiastrea & 63 & 2,33 \\
\hline San hô mềm & 1 & 3,3 \\
\hline
\end{tabular}

Khu vực Khe Con có nền đáy tương đối bằng phẳng với thành phần chủ yếu là đá san hô chết và cát. San hô giống được lấy tại chỗ là giống Plesiastrea phát triển tốt, không tập đoàn nào bị chết và chỉ có 1 tập đoàn đang bị ốc ăn, 1 giá thể bị vỡ vụn do quá trình thả neo tàu thuyền. Tỷ lệ sống vẫn đạt $100 \%$. Nhìn chung san hô trồng trên các giá thể phát triển tốt, các polyp đã phát triển trùm kín các dây buộc. Số lượng địch hại ở khu vực này ít hơn ở hòn Khe Trâu và hòn Đặng Văn Châu.

\section{b. Kết quả trồng san hô trên giá thể tự nhiên}

Đã tiến hành trồng được 30 tập đoàn san hô phủ trên diện tích khoảng $45 \mathrm{~m}^{2}$. Các tập đoàn cũng được gắn thẻ để theo dõi tỷ lệ sống và quá trình sinh trưởng tiếp theo. Kết quả trồng được tổng hợp trong bảng 6 .

Bảng 6: Kết quả trồng san hô trên giá thể tự nhiên tại Khe Con

\begin{tabular}{|c|c|c|}
\hline Tên giống & Số tập đoàn trồng & $\begin{array}{c}\text { Mức tăng trưởng trung bình } \\
(\mathbf{c m} / \mathbf{t a ̣ ̂ p} \text { đoàn/năm) }\end{array}$ \\
\hline Plesiastrea & 30 & 2,35 \\
\hline
\end{tabular}

Sau một năm tổng số tập đoàn bị chết và bị tuột là 4 tập đoàn đạt tỷ lệ sống đạt $86,6 \%$. Hiện có 1 tập đoàn đang bị ốc ăn và 1 tập đoàn bị chết 1 phần do tách chiết và va đập mạnh. Tốc độ tăng trưởng trung bình của giống Plesiastrea trên giá thể tự nhiên tại khu vực hòn Khe Con là 2,35 cm/năm. 


\section{Thảo luận}

- Nhìn chung 10 giống san hô bản địa được trồng trên giá thể tự nhiên và nhân tạo đều phát triển tốt, có thể nhìn thấy bằng mắt thường là các dây buộc san hô vào giá thể đã bị san hô phủ kín, chìm sâu vào trong tập đoàn, các xúc tu vươn dài, màu sắc tươi sáng. Như vậy có thể nói các loài san hô bản địa ở đây đều có khả năng trồng phục hồi tốt.

- Tỷ lệ sống của san hô trồng phục hồi nhân tạo rất cao, đạt từ 70 - 86,6\% sau 1 năm trồng trên giá thể tự nhiên và đạt trên $94 \%$ sau 1 năm trồng trên giá thể nhân tạo dạng vòm. San hô chết có phần tua thối rữa và chỉ chết rải rác ở một số giá thể khác nhau chứng tỏ nguyên nhân gây chết là do các yếu tố cơ học trong quá trình trồng san hô, thời gian giữ san hô trên cạn quá lâu làm chết các xúc tu và không có khả năng phục hồi khi được đưa trở lại môi trường.

- Một vấn đề rất đáng quan tâm hiện nay là sự phát triển của các sinh vật gây hại, điển hình là ốc Drupella. Chúng ăn tất cả các nhóm san hô kể cả nhóm có nhiều gai sắc nhọn như Echinophyllia. Giống ốc này có kích thước nhỏ hay chui rúc trong các khe hoặc 1ỗ trong rạn san hô, khi ăn san hô chúng thường tập chung thành từng nhóm 5 - 6 cá thể ăn hết tập đoàn này chúng lại di chuyển sang tập đoàn khác. Loài ốc này phát triển do sự mất cần bằng sinh thái đặc biệt là hiện tượng khai thác quá mức làm mất các loài cá làm địch hại của chúng như nhóm cá bò, do vậy chúng phát triển rất mạnh. Hiện tượng này đã phát hiện ở khu vực Cát Bà và Hạ Long từ năm 2006.

- Kỹ thuật trồng san hô tương đối đơn giản đặc biệt khi người dân địa phương đã được trực tiếp hướng dẫn phương pháp trồng và nắm được các nguyên lý, thao tác cơ bản. Điều quan trọng là đảm bảo đúng các thao tác, tránh các va chạm cơ học nhiều vào san hô giống, thực hiện nhanh, không để san hô quá lâu trên cạn. Mặc dù các thành viên tình nguyện tham gia trong quá trình trồng đều là những người bơi lặn giỏi nhưng số người có khả năng lặn bằng bình khí rất ít. Đây là cản trở và khó khăn rất lớn cho quá trình trồng và giám sát phát triển san hô vì cần có thời gian làm việc dưới nước dài mà các phương pháp lặn thủ công không đảm bảo an toàn cho quá trình làm việc. Nếu khắc phục được khó khăn này thì việc tạo điều kiện cho người dân tổ chức trồng phục hồi san hô tại quần đảo Cô Tô sẽ rất dễ dàng, khả năng thành công cao.

Như vậy việc trồng phục hồi các rạn san hô tại khu vực Cô Tô hoàn toàn có khả năng thực hiện được trên cả giá thể tự nhiên và nhân tạo. Điều đáng quan tâm hiện nay là tình trạng khai thác quá mức và bằng hình thức huỷ diệt cần sớm được loại bỏ tại khu vực này. Sự mất cần bằng sinh thái đã dẫn đến sự phát triển của các loài gây hại. Nếu được bảo vệ tốt và các hình thức khai thác huỷ diệt được kiểm soát thì những khu vực này có thể là 
nơi phát tán nguồn giống cho khu vực và còn là điểm thăm xem lý tưởng khi Cô Tô trở thành một điểm du lịch hấp dẫn của tỉnh Quảng Ninh.

\section{KẾT LUẬN}

Vào năm 2008, chúng tôi đã tiến hành trồng được tổng số 232 tập đoàn san hô trên 29 giá thể nhân tạo và 95 tập đoàn san hô trên giá thể tự nhiên. Sau 01 năm trồng phục hồi, kết quả cho thấy 10 giống san hô đều có thể sử dụng để trồng phục hồi được với tỷ lệ sống rất cao, đạt trên $94 \%$ ở giá thể nhân tạo dạng vòm và đạt từ $70-86 \%$ trên giá thể tự nhiên. Tốc độ tăng trưởng trung bình sau 1 năm trồng đều đạt trên $1,00 \mathrm{~cm} / \mathrm{năm}$, đạt ở mức trung bình đối với các loài san hô dạng khối và phiến phủ.

Nguyên nhân các tập đoàn san hô buộc gắn vào giá thể bị tuột và sự phát triển của địch hại san hô - ốc Drupella được phát hiện vào tháng 8/2009 đang là mối đe dọa làm giảm tỷ lệ sống của san hô trồng phục hồi nhân tạo trên các loại giá thể tại các khu vực trồng thuộc quần đảo Cô Tô.

\section{TÀI LIỆU THAM KHẢO}

1. Đỗ Văn Khương và nnk, 2005. Nghiên cứu bổ sung cơ sở khoa học cho qui hoạch, quản lý các khu bảo tồn biển Cát Bà và Cô Tô. Báo cáo tổng kết đề tài. Lưu trữ tại Viện Nghiên cứu Hải sản.

2. Nguyễn Đăng Ngải, 2004. Đặc điểm và sự đa dạng của hệ sinh thái rạn san hô khu vực Cát Bà và Cô Tô. Báo cáo chuyên đề đề tài "Cơ sở khoa học cho việc qui hoạch, quản lý các khu bảo tồn biển Cát Bà và Cô Tô". Lưu tại Viện Tài nguyên và Môi trường biển.

3. Võ Sĩ Tuấn, 2005. Cơ sở khoa học hướng dẫn phục hồi hệ sinh thái rạn san hô. Báo cáo chuyên đề đề tài "Nghiên cứu các giải pháp bảo vệ, phục hồi các hệ sinh thái rạn san hô, cỏ biển và khắc phục ô nhiễm môi trường biển tự sinh". Lưu trữ tại Viện Hải dương học.

4. WWF Vietnam Marine Conservation Northern Survey Team, 1994. Survey report on the Biodiversity, Resource Utilization and Conservation Potention of Co to Island, Quang Ninh, North Viet Nam: 1-74. 


\title{
SOME EXPERIMENTAL RESULTS ON TRANSPLANTED CORAL RESTORATION RELYING ON LOCAL COMMUNITIES IN CO TO ISLANDS
}

\author{
NGUYEN DUC CU, NGUYEN DANG NGAI, DAO THI ANH TUYET, NGUYEN VAN THAO, \\ NGUYEN XUAN THANH, NGUYEN DUC TOAN, DOAN THI NHINH
}

\begin{abstract}
Summary: Planting coral restoration associated with local community was implemented at protected areas of Co To islands such as: Khe Trau, Dang Van Chau and Khe Con islets. In April and August 2008, total 232 coral colonies on 29 concreted reefballs and 95 coral colonies on natural substrates were transplanted. The monitoring results after one year showed that, a total of 10 local coral genera can be used for transplanting with very high survival rate (over 94\%) on aftificial substrates and about $70-86 \%$ on natural substrates. The average growth rate of coral colonies was above $1.00 \mathrm{~cm} /$ year.

Due to error attaching process of coral colony on the shelters and the development of coral predator (snail Drupella) in restoration areas that was causes of reduction survival rate of coral on artificial in Co To Islands.
\end{abstract}

Ngày nhận bài: 16 - 7 - 2010

Ngưòi nhận xét: PGS. TS. Trần Đức Thạnh 